\author{
Skorobohatova O. O., \\ Doctor of Philology, Associate Professor, \\ Head of Slavic Lanuages Department \\ of H. S. Skovoroda Kharkiv National Pedagogical University
}

\author{
Panarina I. M., \\ Lecturer of English Phonetics and Grammar Department \\ of H. S. Skovoroda Kharkiv National Pedagogical University
}

\title{
REVIEW OF THE MONOGRAPH BY O. V. CHERNTSOVA "DISCOURSE VARIATION OF WORD COGNITIVE SEMANTICS: THE EXPERIENCE OF INTEGRAL RESEARCH (BASED ON VERBAL PREDICATES КАЗАТЬСЯ, ПОКАЗАТЬСЯ, DEVERBATIVE КАЖИМОСТЬ, PARENTHESIS КАЖETCЯ)”
}

O.V. Cherntsova's monograph "Discourse Variation of Word Cognitive Semantics: the Experience of Integral Research" is devoted to the study of variations in word cognitive semantics in the discourses of different types, which has not been systematically implemented so far. A new research object, qualified as a variation of word cognitive semantics in the contexts of different discourses has been introduced. Verbal predicates казаться, показаться, deverbative кажимость, parenthesis кажется are considered. The theoretical basis of the study is the thesis that the subject's cognitive activity is variable in different types of discourses. It is these variations that $0 . V$. Cherntsova explores. The author relies on the postulate of communicative discursive marking and selective purpose of the analyzed units, which, in her opinion, is confirmed by the lack of them in institutional discourses (business, legal, medical, etc.). The functioning of the units and the variation of their cognitive semantics in everyday, nonfiction, artistic and scientific discourses are studied.

The study consists of the introduction, three parts with conclusions to each of them, general conclusions, references, the list of lexicographic sources and the appendix. The structure of the work is quite logical and corresponds to the intended purpose and tasks.

The introductory part of the monograph (p. 7-21) contains the necessary structural components. The text of the introductory part convinces that the proposed work is relevant, new, theoretically and practically meaningful. Its purpose and tasks appear to be in need of urgent solution for the further development of modern linguo-cognitive theory, which is promoted by the integral method, developed and used by the author, who relied on a lot of factual material.

The relevance of the research is determined by the need to study the types of linguistic meanings and polysemy in the linguocognitological aspect in the modern anthropocentric paradigm. This aspect is essential for the theory of linguistic meaning that has been in the focus of linguists' attention for over a decade. The type of polysemy, introduced and discussed in the paper,

Чернцова Е.В. Дискурсивное варьирование когнитивной семантики слова: опыт интегрального исследования (на материале глагольных предикатов казаться, показаться, девербатива кажимость, парентезы кажется) : монография. Харьков : ХНУ имени В.Н. Каразина, 2019. 426 с. is caused by the discursive variation of the cognitive semantics of a word that has not been monographically investigated so far. From the theoretical and methodological perspectives, the relevance of the work lies in the development and testing of the integral method that combines the approaches and achievements of lexical semantics, syntax, cognitive semantics, communicative linguistics and discursive analysis in a single analytical apparatus.

The methodological balance between atomistic and holistic approaches to the study of the cognitive semantics of the studied words is found and kept in the analyzed research. Synchronic and diachronic methods of linguistics are considered as integral and interrelated components of the integrated methodology developed and used in the thesis. The unity of structural and cognitive methods is caused not only by their consistent use in different sections of the work, but also, above all, by the combination of the main objectives of the study: solving the problem of defining contextual meanings, comprehension of these meanings in different communicative and discursive contexts (the main task of atomistic approach to the studied units) allows to move on performing cognitive tasks - to generalize empirical data, to study the dynamics of conceptualization and to highlight the structure of cognitive processes, in particular.

The scientific novelty of the paper is to develop and confirm a new theoretical view on polysemy, to study the linguocognitive model that explains the emergence and reproduction of new meanings in four different discourses, to formulate discursive "rules" that determine the system of discursive meanings of the analyzed words. The author supplements the theory of two-level organization of cognitive word semantics. The assumption about the conditionality of linguistic semantics by the discursive activity of the speaker and his cognitive experience is proved. Correlation between the cognitive level and the level of superficial linguistic semantics is established. A gestalt scenario (conceptual whole) of the studied conceptual sphere, where the cognitive focus and background are highlighted, is reconstructed for the first time. The data on the historical origin and development of parenthesis is qualified in a new way. The cognitive analysis made it possible to establish a conceptual relationship between derivative words (deverbative and parenthesis) with the reconstructed gestalt scenario. 
The first section of the monograph "Theoretical Background and Methodology of Integral Research" discusses the basic methods used by O.V. Cherntsova in her further work and explains their choice. The author uses synchronous methods, including semanticsyntactic analysis, methods of cognitive linguistics, discursive analysis and methods of communicative grammar. The diachronic analysis covers the study of the history of verbs, the internal form of etymological and derivative types and the history of parenthesis in terms of the formation of the parenthetical position in the sentence. The author of the thesis first assumes, and then asserts that the development of the internal form of the analyzed units influences the creation of a wide range of meanings of the verbs казаться, показаться, deverbative кажимость, parenthesis кажется. She seeks to prove that the internal form is connected with the etymology of the word and at the same time influences its polysemic structure at the synchronous level (p. 62). The development of the internal form of the word theory and the appeal to the diachronic study of parenthesis is a definite and convincing advantage of the work done. This part of the work is done in the traditions of Kharkiv Philological School, develops the theory of the internal word form, which was developed by 0.O. Potebnya and are crucial to the modern theory and philosophy of language (see, for example, the works by V.V. Bibikhin, O.S. Snitko). We consider the findings of the first part on the need to take into account historically conditioned semantics - the internal form of the etymological and derivative type - to produce the process of conceptualization, valuable.

It is advisable to be more consistent in presenting the conclusions. The logic of the material of the section, where the possibilities of the integrated method of research are interpreted, requires focusing on the methods of synchronous linguistics first, but a diachronic approach precedes in the conclusions (p. 75), although its description is at the end of the section. According to the author, this approach allows us to investigate the phenomenon of discursive variation in cognitive semantics in contemporary discourses of different types. Its use is complied with the task of synchronous research.

In the second section, "Typology of Discursive Contexts: Cognitive Semantics of Verbal Predicates, казаться, показаться, Deverbative кажимость in a Discursive Interpretation Mode" O.V. Cherntsova focuses on the developing a typology of discursive contexts and examines the cognitive semantics of particular words in discourses of different types.

The section contains 4 subsections. The cognitive semantics of the predicates казаться, показаться, deverbative кажимость is consistently described in the contexts of everyday discourse, journalistic, scientific and artistic discourses. The semantics of the word показаться is considered in two prepositional constructions: где/откуда показался кто/что and кто/что показался каким/чем and the word казаться in the prepositional construction кто/что кажется каким/чем. Prepositional constructions of a simple and complex sentence are compared and contrasted. The peculiarities of verbal predicates functioning in the contexts of different communicative and discursive types are considered.

Considering polysemantic verbal derivatives to be the words with diffuse semantics that responds to the context environment, Ms. Cherntsova describes the connection of the meaning of the word in the context of the broad semantics of this context and the type of communicative register correctly. The paper uses the classification of registers according to the theory by G.O. Zolotova (reproductive, informative, generative, reactive, voluntary), which is used to differentiate the contextual meanings of polysemantic words of verbal semantics. The author convincingly argues that contextual meaning characteristic according to specified criteria enables to distinguish and characterize the cognitive features of the context, which, in her opinion, explicate the speaker's cognitive activity. This section shows how the speaker's communicative intentions correlate with the cognitive bases of their speech. The results of the conducted cognitive-discursive analysis support the hypothesis about the twolevel nature of the cognitive semantics of the word, where the level of conceptual semantics and the level of superficial linguistic semantics are distinguished conditionally. The interconnection between the contextual meaning of the word and the content of the discursive and cognitive activity of the subject of discourse is established, discourse-forming meta-positions are analyzed. The discrepancies in extra linguistic conditions of the discursive activity, global intentions, communicative strategies, language competence levels of subjects of different discourses are identified. The integral approach developed in the work made it possible to trace the explicated discursive logic of subjects of different discourses, to identify and describe a set of conceptualizations of the word.

The third section "Cognitive semantics and functions of parenthesis кажется in different discursive contexts" offers a cognitive-discursive analysis of the semantics of parenthesis кажется, that is compared with the semantics of the original word. The author identifies and describes four discursive scenarios, each of which is related to a specific interactive meaning and conditioned by dialogical functions in the context. It is shown that, unlike predicates, the studied parenthesis has no conceptual meaning of its own, it is associated with the reflective act of the subject's speech, due to the content of the background context.

The parenthesis кажется, according to O.V. Cherntsova, functions as a marker of reflexive cognitive style associated with a particular narrative strategy of the speaker. Five types of narrative context are identified and eleven discursive meanings of parenthesis in them. The observation of the functioning of parenthesis кажется, in the scientific and journalistic discourse, where its use indicates a gradual transition from a positivist type of thinking to a relativistic one seems noticeable in our opinion.

The researcher paid most attention to the study of the functioning of selected words in artistic discourse. The author explains the differences between the contextual meanings of the parenthesis by the peculiarities of the speaker's cognitive and communicative activities displayed in the context. This determines the nature of the subjective structure of the observer: the subject of the external observer, the subject of speech and the subject of reflection. These positions, as shown in the monograph, may coincide in the character. The subjective structure of a knowledge carrier is of a different nature: the varieties of the subject of background knowledge, the subject of reflection and the subject of speech are described. It is shown that the parenthetical position in "I" and "HE" contexts enables the word artist to create the image of the implicit narrator. Ms Cherntsova argues that the narrative function of the parenthesis is also connected with the ability to "switch" communicative registers (for example, from informative to reproductive). The parenthesis кажется marks a discursive act of explanation. The author of the study refers it to a group of linguistic means that reflect 
the cognitive processes of the narrator and indicate a change in the angle of view of the observer.

The functioning of parenthesis is described in free indirect speech; its use makes the structure of the context complicated, combining two angles of view - from the outside and from the inside.

This research section is a major development in modern syntactic theory, discourse theory and the theory of parenthesis in particular. It expands our knowledge of the contexts of the segmented type, explains the use of contexts with parenthesis with the regard to the discursive intentions and intentions of the speaker.

It is worth mentioning that in the text of the analyzed monograph, in the development of scientific analysis and generalizations, we come across Olena Cherntsova's many significant scientific findings and observations, which testify to the originality and courage of the author's thought. For the first time, the linguocognitive model is created in the monograph, which explains the appearance of different meanings of the word in different discourses.

However, we also have some questions to the author.

In the first section of her dissertation, which outlines its theoretical background, Ms. Cherntsova rightly emphasizes the importance of this or that existing theory for the analysis of selected predicates and parenthesis, but we would like a clearer wording of the author's attitude to those theoretical positions. For example, examining different theories of the correlation of cognitive structures with language structures (p. 36 et seq.) it would be advisable to emphasize which theory and why it is close to the author of the work. The conclusion, which confirms the thesis about the two-level organization of cognitive semantics of the word (p. 341), which the dissertation reaches, completing the research, needs a clearer wording of the author's theoretical position at the beginning of the work, when this thesis is presented as an assumption.

We think that it is important for the researcher to emphasize that there is no clear boundary between cognitive experience and linguistic meaning; the transition from human experience to linguistic meaning is continuous. However, the question arises whether, in this case, it is appropriate to use the notion of "sum" taking into account the diffusion of cognitive semantics (p. 233 and others) in relation to selected generalized contextual meanings. Perhaps it would be better to talk about combination or collection of fixed or highlighted meanings. In our view, this remark becomes significant in cases when it comes to the discursiveinteractive meaning of parenthesis кажется, which, according to Olena Vadymivna, "has no conceptual meaning of its own. It is functionally connected to the reflection of the subject on a cognitive activity, the meaning of which is conditioned by different plans of external context" (p. 342). Is it possible to add nonexistent and diffuse meanings, as suggested, especially paying attention to unspecified number of existing and unlimited potential contexts? In our opinion, this is about combining and crossing of meanings connected to the contextual background and interact in our minds. The term "sum" may be used metaphorically, but metaphors in scientific research and terminology is a dangerous thing, as experts suggest, especially when it comes to new authorial metaphors.

The author of the book argues that the cognitive semantics of verbal predicates казаться, показаться, iconically reflects the ontological process of perception (pp.360-361). According to Ms. Cherntsova, the iconicity of the cognitive semantics of the predicates under consideration is that in contexts with a verbative predicate казаться, показаться the process of perception is conceptualized as a dynamic process. In our opinion, conceptualization of concepts occurs dynamically regardless of the type of predicates, the search and choice of the language form for conceptualization of human cognitive acts is continuous, which is repeatedly pointed out by the author of the monograph herself, speaking about the continuity of the transition from human cognitive experience to language meaning. Therefore, in our opinion, to speak about the iconicity in this sense, the iconicity of these predicates is inappropriate. The second thesis about the iconicity of the cognitive semantics of the predicates казаться, показаться considering the possibility of mistaken or distorted first perception of some contexts with these predicates seems entirely justified and doesn't raise any objection.

The analyzed monograph is a complex, completed, topical research. It has general theoretical, methodological and applied value. Its theoretical positions and the obtained results are well argued and open the way for further linguistic searches in both cognitive and communicative-discursive planes. The integral nature of the research methodology, the theoretical validity, the large empirical material, selected from different types of discourses, make it possible to consider the conclusions made quite plausible.

The publication of Cherntsova's monograph has enriched domestic linguistics with this fascinating new theoretical and methodological study, which has great prospects and outlines new ways of studying word semantics in cognitive and discursive aspects. 